\title{
Bacterias del maíz como aliadas en la producción agroecológica de alimentos
}

\author{
Ignacio Eduardo Maldonado Mendoza y Estefanía Morales Ruiz
}

\begin{abstract}
Resumen
El control biológico de plagas, o biocontrol, consiste en utilizar componentes de origen biológico, como insectos, hongos y bacterias, capaces de antagonizar el crecimiento de otros insectos, hongos y bacterias que dañan cultivos. El biocontrol es una estrategia para disminuir las pérdidas en cultivos derivadas del ataque de plagas, con el propósito de asegurar la producción agrícola sostenible desde un enfoque agroecológico, es decir, amigable con el ambiente. El objetivo de este artículo es presentar un ejemplo de control biológico de una enfermedad en el maíz, la fusariosis -causada por el hongo infeccioso Fusarium verticillioides-, mediante el uso de la bacteria de la rizósfera del maíz Bacillus cereus B25. Asimismo, se discutirá del trabajo realizado para entender los posibles mecanismos que usa esta bacteria para inhibir el crecimiento del hongo fitopatógeno, en específico de las enzimas llamadas quitinasas, capaces de degradar la molécula de quitina que forma la pared celular del hongo y que, en consecuencia, detienen su crecimiento. Finalmente, se plantean las posibles aplicaciones biotecnológicas de los resultados encontrados.
\end{abstract}

Palabras clave: control biológico, bacterias benéficas, fusariosis, maíz.

\section{Maize ASSOCIATED BACTERIA AS ALLIES IN AGROECOLOGICAL FOOD PRODUCTION}

\begin{abstract}
Biological pest control, or biocontrol, uses components of biological origin such as insects, fungi, and bacteria, that are capable of antagonizing the growth of other insects, fungi, and bacteria that damage crops. Biocontrol is a strategy to reduce crop losses derived from pests' attack. Its purpose is to ensure sustainable agricultural production from an agroecological approach, that is, environmentally friendly. The objective of this article is to present an example of biological control of a disease in maize, fusariosis caused by the infectious fungus Fusarium verticillioides-, using the maize rhizosphere bacterium Bacillus cereus B25. We will also discuss about the work carried out to understand the possible mechanisms that this bacterium uses to inhibit the growth of the phytopathogenic fungus, specifically the enzymes called chitinases, capable of degrading the chitin molecule that forms the cell wall of the fungus and, consequently, stop its growth. Finally, the possible biotechnological applications of the results found are considered.
\end{abstract}

Keywords: biological control, beneficial bacteria, fusariosis, maize.

Recepción: 12/10/2020. Aprobación: 30/04/2021. Dol: http://doi.org/10.22201/cuaieed.16076079e.2021.22.4.2 
"Bacterias del maíz como aliadas en la producción agroecológica de alimentos" Ignacio Eduardo Maldonado Mendoza y Estefanía Morales Ruiz

Vol. 22, Núm. 4, julio-agosto 2021

Revista Digital Universitaria

Ignacio Eduardo Maldonado Mendoza

imaldoma@ipn.mx

orcid.org/0000-0001-9952-1508

Doctor en Filosofía en Biología Molecular de Plantas en Texas A\&M University. Dirige el Laboratorio de Ecología Molecular de la Rizósfera en el Departamento de Biotecnología Agrícola del cIIDiR-Unidad Sinaloa del Instituto Politécnico Nacional (IPN). Su interés principal es el desarrollo de productos agrobiológicos para el control de enfermedades causadas por hongos fitopatógenos y el estudio de las complejas asociaciones entre microorganismos y plantas (asociaciones tripartitas: planta / bacteria benéfica / hongo fitopatógeno) y sus mecanismos moleculares de interacción.

\section{Estefanía Morales Ruiz}

esmoru@gmail.com orcid.org/0000-0002-3722-015X

Doctora en Ciencias por la Universidad Nacional Autónoma de México (UnAM). Se encuentra realizando una estancia posdoctoral sobre la simbiosis de algas unicelulares con cnidarios. Está interesada en los mecanismos moleculares involucrados en las vías de señalización celular en microorganismos.

\section{Introducción}

Asegurar la producción de alimentos necesarios para abastecer a la población mundial se ha convertido, en los últimos años, en el tema central de un intenso debate. Diversos reportes demuestran que, a escala global, consumimos más de lo que producimos. Esta situación podría volverse insostenible en una veintena de años, por tanto, se buscan y estudian diversas alternativas para resolver el problema de la escasez de alimentos.

A la fecha, se han planteado diversos enfoques, por ejemplo: mejorar o aumentar la producción agrícola, mejorar la distribución de los alimentos, y disminuir las pérdidas en los cultivos. Cada uno de ellos tiene su propia importancia en la cadena de producción de alimentos, y en este trabajo discutiremos la estrategia de disminuir las pérdidas derivadas de los ataques de plagas a los cultivos.

Se considera como plaga a cualquier vegetal, animal o agente patógeno dañino para las plantas. Para contrarrestar sus efectos, se usan diversos plaguicidas químicos, que habían funcionado con cierto éxito, hasta que empezaron a surgir las plagas resistentes a ellos. La resistencia a plaguicidas se da de manera natural cuando en los organismos expuestos a ellos se seleccionan mecanismos u ocurren mutaciones genéticas que les permiten resistir y sobrevivir a los efectos del plaguicida. Además, el uso de plaguicidas comenzó a mostrar consecuencias colaterales dañinas: se acumula en los suelos y son tóxicos para la salud humana y animal; además, atacan organismos que no son su objetivo y que en algunos casos eran benéficos para el cultivo en cuestión (World Health Organization [WHO], 2010). 
"Bacterias del maíz como aliadas en la producción agroecológica de alimentos" Ignacio Eduardo Maldonado Mendoza y Estefanía Morales Ruiz

Vol. 22, Núm. 4, julio-agosto 2021

Revista Digital Universitaria

\section{El control biológico de plagas}

Entonces, ¿qué hacer al respecto? Una primera idea es mejorar los plaguicidas sintéticos que ya existen o buscar algunas sustancias químicas aún mejores, esto es, hacerlos más selectivos y menos persistentes en el ambiente y lograr que sus productos de descomposición no presenten efectos adversos al ambiente o la salud humana. Una alternativa más ecológica es usar plaguicidas de origen natural. Esta estrategia se denomina control biológico (св) de plagas, ya que utiliza componentes de origen biológico, como insectos, hongos y bacterias, capaces de antagonizar el crecimiento de otros insectos, hongos y bacterias que dañan cultivos. Este tipo de control de plagas tiene un enfoque agroecológico, es decir, está orientado hacia la sostenibilidad de los cultivos agrícolas, lo que implica que tiene efectos negativos mínimos. Así, al no liberar sustancias tóxicas al ambiente, se puede preservar la fertilidad y salud de los suelos de cultivo, y utilizar los recursos propios del ecosistema agrícola (Gliessman, 2017).

A los organismos usados en el cB les llamamos benéficos y es interesante investigar los mecanismos que los hacen capaces de aniquilar distintas plagas. Su estudio comienza con su aislamiento, el cual, en general, se logra recolectándolos de los mismos cultivos de interés. Una vez aislados, se clasifican y se evalúa su capacidad de antagonizar alguna plaga determinada, a lo que le llamamos su potencial antagónico. De esta manera, de entre varios candidatos, podemos elegir a los mejores para probar su efecto en el campo. Al día de hoy, se ha demostrado plenamente la eficacia de diversos insectos, hongos y bacterias como agentes de cB.

¿Pero cómo lo hacen? ¿Cómo un organismo puede evitar que otro similar crezca? Y cuando vemos que funciona, ¿cómo lo podemos aplicar para disminuir las pérdidas en los cultivos? Contestar esas preguntas no ha sido nada sencillo; de hecho, hay diversos grupos de investigación tratando de entender los procesos que permiten que un organismo antagonice a otro. Y no sólo eso, también se investiga la manera de aplicar ese conocimiento.

\section{Bacterias benéficas que combaten infecciones en cultivos de maíz}

En nuestro grupo de investigación, hemos trabajado con bacterias benéficas que antagonizan hongos que afectan el maíz. Nuestra área de trabajo es el norte del estado de Sinaloa donde el cultivo de este cereal se realiza de manera intensiva. Se sabe que, en los cultivos de esta zona, se pueden alcanzar pérdidas de hasta $10 \%$ en la producción por efecto particular de infecciones causadas por hongos de la familia Fusarium.

Dicho grupo de hongos se caracteriza por vivir dentro de la planta de maíz (ver figura 1), y por provocar que los tallos y las mazorcas se pudran, una enfermedad llamada fusariosis. Además, producen unas toxinas llamadas 
Figura 1. Imagen obtenida con un microscopio de fluorescencia, donde se observa un corte transversal de una raíz de maíz (en rojo) invadida por Fusarium verticillioides (en verde). Imagen modificada de Leyva-Madrigal et al., 2015.

Figura 2. Micrografía de Fusarium verticillioides (CDC y Ajello, 1978). fumonisinas, que son dañinas para la salud humana y animal. Cabe resaltar que la erradicación de estos hongos endófitos es muy difícil mediante el uso de pesticidas, dado que viven dentro de la planta (Leyva-Madrigal et al., 2015). En este sentido, una estrategia interesante es la búsqueda de agentes de св que minimicen esta infección.

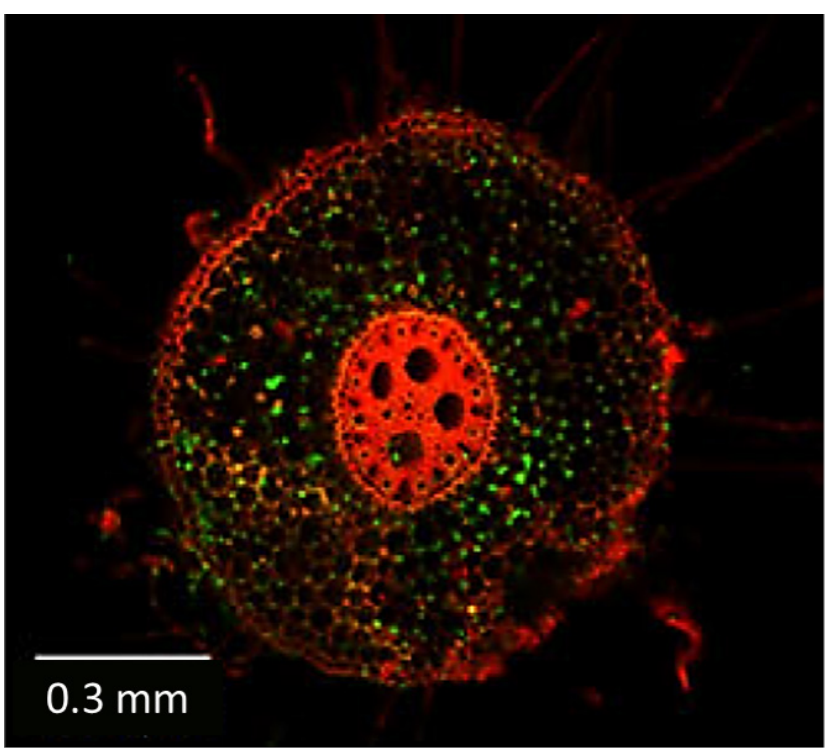

Se han aislado miles de bacterias que habitan en el espacio más cercano a las raíces - la rizósfera - del maíz o el interior de las mismas raíces, y se ha valorado su capacidad potencial para combatir al hongo Fusarium verticillioides (FigueroaLópez et al., 2016; ver figura 2). Las cepas más robustas se han evaluado en campo y se ha demostrado su efecto inhibitorio sobre el crecimiento del hongo y, por lo tanto, en la severidad de la infección.

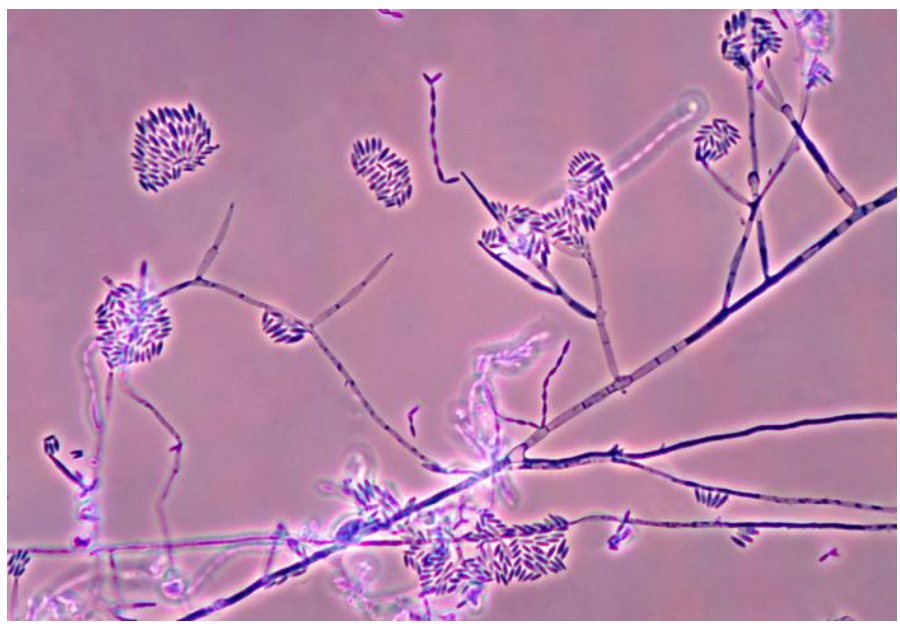

Las diferentes pruebas de campo han permitido seleccionar una bacteria, Bacillus cereus sensu lato cepa B25, que vive dentro de la raíz del maíz (ver figura 3). Esta cepa resultó ser la mejor para inhibir el crecimiento del hongo F. 
Figura 3. Imagen obtenida con un microscopio de fluorescencia. Se observa un corte longitudinal de una raíz de maíz (en naranja), colonizada en el tejido vascular por la bacteria Bacillus cereus sensu lato cepa B25 (en verde). Imagen modificada de FigueroaLópez, M. A. 2016. verticillioides y mejorar el crecimiento del maíz (Lizárraga-Sánchez et al., 2015, Figueroa-López, 2016). Con esta cepa, se realizaron formulados en polvo que se adhieren a las semillas de maíz y las hacen menos susceptibles a infecciones por F. verticillioides (Martínez-Álvarez et al., 2016). De manera paralela a su aplicación en cultivos, se estudian los mecanismos que esta bacteria emplea para impedir el crecimiento del hongo.

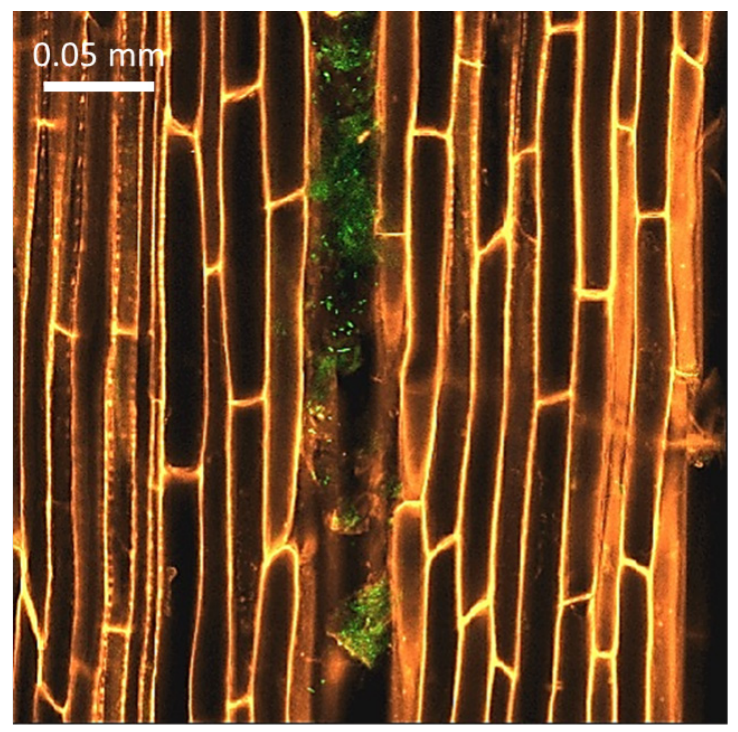

\section{Las quitinasas}

El estudio de los mecanismos que inhiben el crecimiento del hongo F. verticillioides ha permitido establecer la participación de una familia de enzimas llamadas quitinasas. Estas enzimas hidrolíticas son responsables de la degradación de la quitina, molécula que forma parte integral de la pared celular de los hongos. La quitina es una cadena formada por bloques de una molécula llamada N-acetil glucosamina (GIcNAc), que está presente en hongos, nemátodos, crustáceos y artrópodos. Es decir, las quitinasas degradan la pared del hongo que está creciendo e impiden su desarrollo normal. Las quitinasas no son generadas de manera exclusiva por bacterias, también las producen insectos, hongos, plantas e incluso nosotros los humanos.

La cepa B25 de Bacillus cereus sensu lato produce dos quitinasas Ilamadas ChiA y ChiB (Douriet-Gámez, et al., 2017). Se ha demostrado que ambas enzimas son capaces de romper la quitina presente en el hongo F. verticillioides (FigueroaLópez et al., 2017; Morales-Ruiz et al., 2021), lo que impide que el hongo crezca (ver figura 4). El hecho de que tanto el hongo patógeno como la bacteria benéfica vivan adentro de la raíz tiene una implicación importante: la presencia de residuos de quitina degradada (quito-oligómeros) desencadena una respuesta de defensa en la planta, que le ayuda a defenderse mejor del hongo que la está infectando. 
Figura 4. Imágenes obtenidas con un microscopio óptico de un experimento de inhibición del crecimiento de Fusarium verticillioides por la presencia de quitinasas. Se pueden observar conidios de $F$ - un conidio es una espora de origen asexual e inmóvil, la cual germina para dar lugar a hifas (células alargadas) que a su vez forman al hongo-. verticillioides (algunos señalados con flechas) que en condiciones normales (panel A) germinan y forman hifas (estructuras alargadas) mientras que en presencia de quitinasas (panel B) los conidios no germinan o lo hacen de manera deficiente (señalado con un asterisco). Imagen modificada de MoralesRuiz, et al., 2021

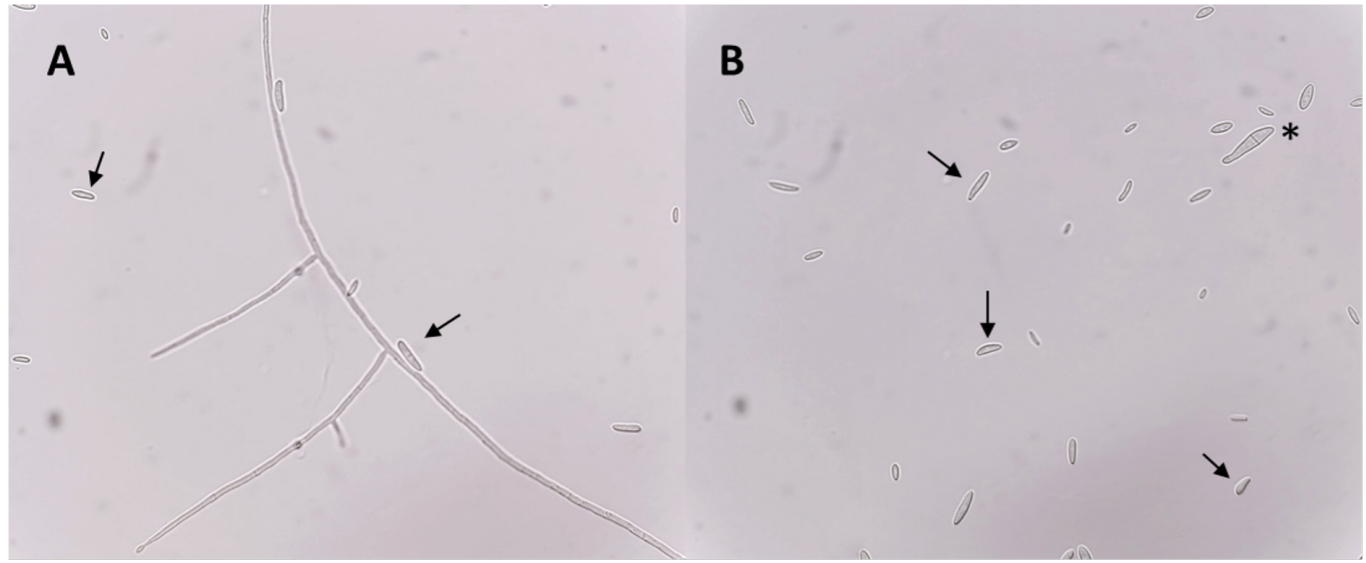

Así, las quitinasas son enzimas importantes. De hecho, hay investigaciones que están tratando de mejorar su actividad, para hacerlas más efectivas en el combate contra patógenos, y otras que están aislando microorganismos quitinolíticos que produzcan quitinasas naturalmente destacables.

Además de la cepa B25 de Bacillus cereus sensu lato, se han reportado otros grupos de bacterias que producen quitinasas, entre las que se encuentran Chromobacterium, Pseudomonas, Streptomyces y Serratia. Podemos observar, entonces, que los microorganismos quitinolíticos se distribuyen de manera amplia en la naturaleza, y son blancos potenciales de desarrollo biotecnológico. A la fecha, adicionalmente a su aplicación en la rama agrícola, las quitinasas obtenidas de algunas de las bacterias arriba mencionadas se utilizan para tratar desechos de quitina de la industria camaronera y para mejorar la producción de bioetanol (Stoykov et al., 2014).

Sin embargo, pocas quitinasas están disponibles de manera comercial. Por ello, se propone que aumentar el conocimiento y la evidencia de los beneficios que se pueden obtener mediante el uso de quitinasas purificadas o microorganismos quitinolíticos se reflejará en un aumento de la demanda en su producción y aplicación.

\section{Conclusiones}

En conclusión, las bacterias quitinolíticas son una excelente materia prima para desarrollar productos amigables con el ambiente, que pueden ser aplicados en una agricultura sustentable que permita disminuir las pérdidas en los cultivos y contribuir a la seguridad alimentaria.

\section{Referencias}

* CDC y Ajello, L. (1978). [Fotomicrografía de Fusarium verticillioides]. Public Health Image Library. https://phil.cdc.gov/Details.aspx?pid=4010 
"Bacterias del maíz como aliadas en la producción agroecológica de alimentos" Ignacio Eduardo Maldonado Mendoza y Estefanía Morales Ruiz

Vol. 22, Núm. 4, julio-agosto 2021

Revista Digital Universitaria

* Douriet-Gámez, N. R., Maldonado-Mendoza, I. E., Ibarra-Laclette, E., Blom, J. y Calderón-Vázquez, C. L. (2018). Genomic analysis of Bacillus sp. strain B25, a biocontrol agent of maize pathogen Fusarium verticillioides. Curr Microbiol, 75, $247-$ 255. https://doi.org/10.1007/s00284-017-1372-1

* Figueroa-López. A. M., (2016). Caracterización del mecanismo de antagonismo que emplea Bacillus cereus seleccionada para el control de Fusarium verticillioides. [Tesis de maestría, Instituto Politécnico Nacional]. http://rdcb.cbg.ipn.mx/ handle/20.500.12273/692

* Figueroa-López, A. M., Cordero-Ramírez, J. D., Martínez-Álvarez, J. C., López-Meyer, M., Lizárraga-Sánchez, G. J., Félix-Gastélum, R., Castro-Martínez, C. y MaldonadoMendoza, I. E. (2016). Rhizospheric bacteria of maize with potential for biocontrol of Fusarium verticillioides. SpringerPlus, 5, 330. https://doi.org/10.1186/s40064-016$1780-x$

* Figueroa-López, A. M., Leyva-Madrigal, K. Y., Cervantes-Gámez, R. G., BeltránArredondo, L. I., Douriet-Gámez, N. R., Castro-Martínez, C. y Maldonado-Mendoza, I. E. (2017). Induction of Bacillus cereus chitinases as a response to lysates of Fusarium verticillioides. Rom Biotech Lett, 22(4), 12722-12731. https://e-repository. org/rbl/vol.22/iss.4/6.pdf

* Gliessman, S. R. (2017). La agroecología: un movimiento global para la seguridad y la soberanía alimentaria. Agroecología para la seguridad alimentaria y nutrición: actas del Simposio Internacional de la FAO. Roma. http://www.fao.org/3/i4729s/ i4729s.pdf

* Leyva-Madrigal, K. Y., Larralde-Corona, C. P., Apodaca-Sánchez, M. A., QuirozFigueroa, F. R., Mexia-Bolaños, P. A., Portillo-Valenzuela, S., Ordaz-Ochoa, J. y Maldonado-Mendoza, I. E. (2015). Fusarium species from the Fusarium fujikuroi species complex involved in mixed infections of maize in northern Sinaloa, Mexico. J Phytopathol, 163(6), 486-497. https://doi.org/10.1111/jph.12346

* Lizárraga-Sánchez, G.J., Leyva-Madrigal, K. Y., Sánchez-Peña, P., Quiroz-Figueroa, F. R. y Maldonado-Mendoza, I. E. (2015). Bacillus cereus sensu lato strain B25 controls maize stalk and ear rot in Sinaloa, Mexico. Field Crops Res, 176, 11-21. https://doi. org/10.1016/j.fcr.2015.02.015

* Martínez-Álvarez, J. C., Castro-Martínez, C., Sánchez-Peña, P., Gutiérrez-Dorado, R. y Maldonado-Mendoza, I. E. (2016). Development of a powder formulation based on Bacillus cereus sensu lato strain B25 spores for biological control of Fusarium verticillioides in maize plants. World J Microb Biot, 32(5). https://doi.org/10.1007/ s11274-015-2000-5

* Morales-Ruiz, E., Priego-Rivera, R., Figueroa-López, A. M., Cazares-Álvarez, J. E. y Maldonado-Mendoza, I. E. (2021). Biochemical characterization of two chitinases from Bacillus cereus sensu lato B25 with antifungal activity against Fusarium verticillioides P03. FEMs Microbiol Lett, 368(2), fnaa218. https://doi.org/10.1093/ femsle/fnaa218

* Stoykov, Y. M., Pavlov, A. I. y Krastanov, A. I. (2015). Chitinase biotechnology: production, purification, and application. Eng Life Sci, 15(1), 30-38. https://doi. org/10.1002/elsc.201400173 
"Bacterias del maíz como aliadas en la producción agroecológica de alimentos" Ignacio Eduardo Maldonado Mendoza y Estefanía Morales Ruiz

Vol. 22, Núm. 4, julio-agosto 2021

Revista Digital Universitaria

* World Health Organization (wHo). (2010). Código internacional de conducta sobre la distribución y utilización de plaguicidas: directrices para el registro de plaguicidas (No. WHO/HTM/NTD/WHOPES/2010.7). https://apps.who.int/iris/handle/10665/70602

\section{Cómo CITAR ESTE ARTículo}

* Maldonado Mendoza, Ignacio Eduardo y Morales Ruiz, Estefanía. (2021, julio-agosto). Bacterias del maíz como aliadas en la producción agroecológica de alimentos. Revista Digital Universitaria (), 22(4). http://doi.org/10.22201/cuaieed.16076079e.2021.22.4.2 